\title{
POLA TINGGAL, PERAWATAN KEBERSIHAN DAN KESEHATAN LANJUT USIA DALAM RUMAH TANGGA PADA KOMUNITAS ETNIS TIONGHOA DI PEGUNUNGAN SALIUNG SINGKAWANG KALIMANTAN BARAT (SUATU KAJIAN SOSIAL BUDAYA)
}

\author{
WAY OF LIVING, CLEANLINESS AND HEALTHY TREATMENT OF \\ ELDERLY IN THE HOUSEHOLD OF TIONGHOA ETHNIC COMMUNITY \\ IN SALIUNG SINGKAWANG MOUNTAIN RANGE, WEST KALIMANTAN \\ (A SOCIAL CULTURE STUDY)
}

\section{Oleh I m r a n ${ }^{1}$ ABSTRACT}

Background: The increasing number of elderly becomes the main problem related with physical, economy and social conditions. Elderly who lives in isolated area will aggravate their living process. Community of Tionghoa ethnic who live in the Saliung mountain is a group of community who have ever been eliminated socially or politically.

Objective: This research was aimed to find out problems that related with way of living, hygiene and health codition of elderly in the household of Tionghoa ethnics community.

Method: This was a qualitative research that used social culture approach and intrinsic case study (participatory) design. This research was implemented in Saliung mountain range in the village of Sedau, sub district of South Singkawang, West Kalimantan. The sought variable was way of living, knowledge, attitude and personal hygiene and health behavior. Information was obtained from elderly, community, health officer, village officials, tradition and culture institution that oriented on triangulation. Data was presented in the form of diagram, documentation, direct reference and description.

Result: This research was succeed in exploring knowledge, attitude and behavior of elderly in the household and various aspects that were related with the living of elderly and community of Tionghoa ethnic generally, including personal hygiene as the effect of high work productivity so that time and opportunity is very limited for for personal care.

${ }^{1}$ Imran : dosen Program Studi Penjaskesrek FKIP Untan 
Conclusion: Problems of way of living, personal hygiene and health condition of Tionghoa ethnic community in Saliung mountain were related with perspectives in order health intervention to succeed.

Keyword: way of living, cleanliness and healthy treatment of Tionghoa Saliung elderly, social culture.

\section{PENDAHULUAN}

Tujuan pembangunan kesehatan adalah untuk meningkatkan kesadaran, kemauan dan kemampuan hidup sehat bagi setiap orang agar terwujud derajat kesehatan yang optimal. Upaya yang ditempuh pemerintah adalah menjadikan pembangunan nasional yang berwawasan kesehatan sebagai suatu strategi nasional menuju Indonesia sehat 2010 (UU.Kes.No.23, 1992).

Pada saat ini, proses penduduk yang menua dihadapi hampir semua negara di dunia, termasuk Indonesia. Pada tahun 2000 jumlah penduduk lanjut usia (lansia) mencapai sekitar 15.958.400. Jumlah tersebut tercatat hampir $8 \%$ dari seluruh penduduk Indonesia, jumlah penduduk lanjut usia meningkat 15,9 \% dari tahun 1995-2000 (Policy Brief, 2001).

Dengan meningkatnya lanjut usia, berarti juga terjadi peningkatan kesehatan termasuk perbaikan gizi dan pelayanan kesehatan. Namun demikian semakin tua lansia apalagi menjelang di atas 70 tahun, maka terjadi pula peningkatan masalah kesehatan yang sangat kompleks, lanjut usia akan mempunyai ketergantungan yang tinggi secara fisik, mental maupun sosial baik terhadap individu, keluarga maupun masyarakat, terutama bagi lanjut usia yang tidak produktif ( Silaswati, 2000). Ketergantungan lanjut usia tersebut umumnya berkait dengan masalah ekonomi dan terutama pemenuhan kebutuhan sehari-hari (Messent, 1998).

Keterbatasan ekonomi keluarga dalam menopang kehidupan lanjut usia termasuk kesehatannya menjadi beban sendiri dalam keluarga, sehingga upaya kesejahteraan lanjut usia juga semakin berkurang, apalagi sekitar $60 \%$ lanjut usia yang menyatakan tidak bekerja menggantungkan hidupnya pada anaknya untuk kehidupan sehari-hari (Fatturochman dan Kusumasari, 2001). Brubaker (1994) mengatakan bahwa kebutuhan lanjut usia sebagian besar menjadi sangat tergantung (dependent older people) pada orang lain, yaitu ketergantungan pada kebutuhan keuangan (financial needs), kebutuhan fisik (physical needs) dan kebutuhan emosional sosial, yaitu kebutuhan untuk berinteraksi dan melakukan kontak sosial.

Meningkatnya arus modernisasi dan era kompetisi, menyebabkan kesibukan keluarga semakin bertambah, sehingga perhatian kepada lanjut 
usia menjadi berkurang dan akibatnya penduduk lanjut usia menjadi terlantar (Emilia, $d k k, 1995)$. Keadaan tersebut pada akhirnya membuat lanjut usia cenderung disingkirkan karena tidak produktif, sulit diajak kerjasama, dapat menghambat bahkan dianggap pikun (Matindas, 1994).

Setiap keluarga memiliki pengetahuan dan informasi mengenai kesehatan dan berbagai cara untuk mempertahankan kesehatan anggota keluarganya. Tingkat pengetahuan ini amat dipengaruhi oleh tingkat pendidikan, status sosial ekonomi dimana keluarga itu berada dan kepercayaan tentang cara mempertahankan kesehatan yang diwarisi dari para orang tua sebelumnya (Nurrochmah, 1998). Beberapa sikap keluarga terhadap lanjut usia dirumah seperti yang dikemukakan oleh Rahayu (1996) adalah 1) Menerima dan merawat di rumahnya, 2) Menolak dan tidak mau merawat di rumahnya dan 3) Adalah orang lanjut usia sendiri yang menolak dan tidak mau dirawat di rumah anaknya (tinggal bersama anaknya). Ketiga sikap di atas terjadi karena beberapa alasan, diantaranya adalah keadaan sosial ekonomi keluarga, persepsi negatif keluarga terhadap lanjut usia dan lanjut usia sendiri menjadi beban keluarga. Sebagaimana yang dinyatakan oleh Murti (1997) bahwa lanjut usia juga dianggap sebagai beban ekonomi yang akhirnya tidak disenangi. Pada hal suasana keluarga yang bersahabat akan menambah kualitas hidup yang bersangkutan.

Komunitas Tionghua merupakan etnis terbesar dari seluruh penduduk yang ada di daerah Singkawang, tersebar di berbagai wilayah pedesaan dan di pegunungan saliung. Pada umumnya mereka bekerja sebagai pedagang, buruh dan petani. Sedangkan komunitas etnis Tionghoa yang bemukim di desa Sakkok berjumlah 147 kepala keluarga, lanjut usia yang berusia 60 tahun atau lebih hanya berjumlah 17 orang. Umumnya bekerja sebagai petani sayur, mereka menggarap dan menggunakan lahan di sekitar (di bawah) pegunungan saliung. Kehidupan etnis Tionghoa di daerah ini cukup memprihatinkan terutama golongan lanjut usia, hal ini apabila dilihat dari perilaku hidup bersih dan sehat. Pada umumnya komunitas etnis Tionghoa ini selain bertani sayur juga menggunakan lahan untuk berternak seperti babi, ayam, bebek, hewan-hewan ternak tersebut ada yang ditempatkan dikandang ada pula yang dilepas/berkeliaran. Lokasi pemeliharaan ternak ini sangat dekat dengan lingkungan rumah tinggal mereka, sehingga menimbulkan pencemaran baik udara, air maupun kuman-kuman penyakit dari hewan ternak tersebut. Berdasarkan data profil Puskesmas Tanjung Batu tahun 2003, bahwa penyakit kulit (dermatitis) adalah jenis penyakit yang berada pada urutan ke 5 dari 10 besar penyakit. Sedangkan dari segi sosial dan ekonomi komunitas di daerah ini termasuk penduduk miskin hal ini terlihat dengan adanya bantuan program Jaring Pengaman Sosial (JPS) yang diperoleh sejak 
tahun 1998 sampai dengan tahun 2003. Selain itu, penduduk golongan lanjut usia tidak pernah mengalami pendidikan formal, sehingga golongan lanjut usia ini tidak dapat membaca dan menulis.

\section{PERUMUSAN MASALAH}

Berdasarkan uraian di atas, maka perumusan masalah dalam penelitian ini adalah bagaimana keadaan kebersihan, kesehatan, dukungan perawatan, pengetahuan, sikap dan perilaku dan peran sumber daya dengan pola tinggal yang diinginkan oleh lanjut usia.

\section{TUJUAN PENELITIAN \\ Tujuan Umum}

Tujuan dari penelitian ini adalah mengetahui masalah pola tinggal, perawatan kebersihan diri (pengetahuan, sikap, perilaku), dukungan perawatan sesuai dengan sumber daya yang ada. Penelitian ini diharapkan dapat memberikan manfaat : 1) Bagi lanjut usia sendiri yang hidup di lingkungan keluarganya, mempunyai konsep yang berhubungan dengan perawatan diri dan kesehatan yang secara mandiri dapat menjaga status kesehatannya; 2) Bagi para peneliti sebagai suatu bahan diskusi dalam penelitian kelompok lanjut usia yang berbasis partisipatif; 3) Bagi peneliti selanjutnya sebagai bahan untuk menambah wawasan dan pengetahuan dalam bidang sosial budaya dan kemasyarakatan yang erat kaitannya dengan masalah kesehatan lanjut usia.

\section{METODE PENELITIAN}

\section{Desain Penelitian}

Penelitian ini merupakan penelitian kualitatif dengan pendekatan sosial budaya. Teknik yang digunakan dalam pengumpulan data adalah teknik partisipatif, rancangan yang digunakan adalah studi kasus intrinsik yang bertujuan untuk mengeksplorasi masalah pola tinggal, perawatan kebersihan dan kesehatan lanjut usia di lingkungan keluarga.

\section{Subjek Penelitian}

Subjek penelitian ini adalah lanjut usia yang berumur 60 tahun atau lebih dan masih dapat berkomunikasi secara aktif serta tinggal dalam lingkungan keluarga etnis Tionghua. 


\section{Analisis Data}

Analisis utama dalam penelitian ini adalah analisis isi (content analysis) sebagaimana menurut Miles dan Huberman (1992) yakni menggunakan model interaktif, sebagai berikut:

\section{Pengumpulan data}

Pengumpulan data dengan wawancara mendalam (indepth interview), Focus Group Discusion (FGD) dan observasi terstruktur. Hasilnya direkap dalam pita kaset, catatan-catatan di lapangan dan disalin dalam bentuk transkrip.

\section{Validitas dan Reliabilitas \\ Validitas Internal}

Pada penelitian kualitatif, validitass internal (credibility) dilakukan dengan Triangulasi. Triangulasi adalah teknik pemeriksaan data yang memanfaatkan sesuatu yang lain di luar data itu untuk keperluan pengecekan atau sebagai pembanding terhadap data itu. Ada 4 macam triangulasi sebagai teknik pemeriksaan yang memanfaatkan sumber, metode, penyidik dan teori (Moleong, 2002). Dalam pelaksanaan penelitian ini digunakan triangulasi dengan sumber dan metode. Triangulasi dengan sumber berarti membandingkan dan mengecek balik derajat kepercayaan suatu informasi yang diperoleh melalui sumber yang berbeda, serta membandingkan keadaan masyarakat dengan berbagai pandangan dan pendapat orang lain. Sedangkan Triangulasi dengan metode, dengan cara pengecekan derajat kepercayaan penemuan hasil penelitian dengan beberapa teknik pengumpulan data, yaitu Indepth interview, FGD dan observasi.

\section{Reliability (Dependability)}

Reliabilitas atau tingkat ketetapan, dilakukan dengan cara auditing data (Muhadjir, 1996). Dalam pelaksanaan penelitian ini, setiap data atau informasi yang diperoleh dianalisis secara terus menerus untuk mengetahui maknanya dihubungkan dengan masalah penelitian.

\section{HASIL DAN PEMBAHASAN Hasil Penelitian}

1. Karakteristik informan

Informan yang dipilih adalah lanjut usia berumur 60 tahun atau lebih yang berjumlah 14 orang, terdiri dari 13 orang lanjut usia laki-laki dan 1 orang lanjut usia perempuan. Informan tersebut dibagi menjadi 7 orang 
sebagai peserta FGD dan 7 orang sebagai informan dalam kegiatan indepth interview. Sedangkan untuk keperluan data observasi dilakukan kepada seluruh informan. Pada umumnya informan berstatus menikah (bersuami/istri) dan bekerja sebagai petani sayur, tidak pernah mengalami pendidikan. Agama/kepercayaan yang dianut adalah Konficius/Konghucu.

\section{Pola tinggal}

a. Pola tinggal yang diinginkan lanjut usia

Pola kehidupan komunitas etnis Tionghoa selalu identik dengan ajaran dan kepercayaannya, terutama bagi etnis Tionghua lanjut usia. Sehingga seluruh aktivitas kehidupannya tidak akan pernah lepas dari nilai-nilai tradisi, budaya dan kepercayaannya. Perilaku lanjut usia untuk bermukim dan hidup pada suatu tempat tertentu harus berpedoman pada nilai-nilai tradisi dan budaya serta kepercayaan. Hal ini kalau tidak dilaksanakan, maka akan mengalami suatu penderitaan dalam proses perjalanan hidupnya selama berada di alam dunia. Sebagaimana petikan berikut ini :

“.......Thok jit cak bi.... Thongnyien jit jong-jong thok sang shi oy.... thok $k u$ atau konhi mothok tem......ngai he tiawli" (.........pilih untuk tinggal .......kalau orang Tionghoa sama dengan pilih hidup dan mati .... Mau pilih susahkah atau mau senang...... tak boleh salah pilih harus ikut aturannya, FGD).

Dengan pegangan hidup yang sangat kuat sehingga dalam pemenuhan untuk bermukimpun sebagai pilihan hidup dan mati.

b. Pilihan tempat tinggal

Kehidupan lanjut usia pada umumnya banyak dipengaruhi oleh kondisi fisik dan psikologis meskipun situasi dan kondisi daerah pemukiman sangat menunjang. Pada suatu saat lanjut usia pasti mengalami kesulitan dalam memelihara dan mengawasi dirinya, sehingga pada akhirnya lanjut usia pasti membutuhkan orang lain sebagai tumpuan hidupnya. Sebagaimana petikan berikut ini :

"Nghai ti ...akung thay shie thongnyien laichi ko thay fu chit pie moy chi he low chika ....bon pun lai chi fu cit.... ju pungki tewlu fucit ka ja'oy to shi " (Yang saya tahu...... Sejak nenek moyang ajaran Tionghua selalu melihat anak laki-laki itu lebih besar nilainya darii perempuan .... Kalau sudah tua kita kasik ganti tanggung jawab anak laki-laki...ada usaha berikan dia sampai tanggung jawab urus orang tuanya sampai mati, IND). 
Rata-rata lanjut usia lebih memilih tinggal bersama anak laki-laki, hal ini karena berhubungan dengan nilai-nilai budaya dan kepercayaan bahwa clan pancaran anak laki-laki lebih dominan dari pada perempuan.

c. Lingkungan tempat tinggal

Dalam menentukan dan menetapkan cara membuat rumah tinggal komunitas etnis Tionghoa sangat berpegang teguh pada nilai-nilai budaya dan kepercayaan (Conficius), sehingga salah satu pilihan alternatif dalam kehidupan ini adalah cara membuat rumah tinggal yang sesuai dengan ketentuan ajaran dan kepercayaan mereka. Sebagaimana petikan berikut ini:

"He chow buhk oy ju chikkah pungsi ... chikkah fongsui an chong...cut shieh ....nyik chi he co'to emho " (kalau membuat rumah tinggal ...harus sesuai dengan keadaan diri kita fungsui kita ...misalnya tanggal lahir...hari lahir...kalau letak rumah salah bisa salah jalan hidupnya, FGD)

d. Problem kehidupan lanjut usia

Sikap hidup etnis Tionghoa selalu memegang teguh tradisi nenek moyang leluhurnya, terutama pola kehidupan yang didasarkan pada konsep hidup menurut ajaran Confucius. Kehidupan komunitas Etnis Tionghoa dipegunungan Saliung cukup memprihatinkan hal ini dikarenakan daerah ini dikategorikan penduduk miskin. Sebagaimana petikan berikut ini :

" Liha sang'an singkhu senli...tju cut nyip... sen chu he kew shit ..... oi kak nyin thu an siauw lie " ( sekarang hidup tambah susah...usaha masuk tak sesuai dengan keluar .......usaha pas-pasan hanya untuk makan, untuk hiduppun cukuplah, minta sama orang malu, FGD).

3. Keadaan kebersihan lanjut usia

a. Perawatan kebersihan diri

Berdasarkan observasi bahwa lanjut usia komunitas etnis Tionghoa dipegunungan Saliung dalam melaksanakan perawatan kebersihan diri tergantung dari kemauan dan waktu aktivitas sehari-hari, semakin banyak mereka melakukan aktivitas kerja di sawah, maka semakin rendah perhatian dan kemauan melakukan perawatan kebersihan diri. Sebagaimana petikan berikut ini :

"He seliong mo thin cok shaken... co-co hi jantu mo seliong ..... kiw tiam ngai chon jang ha ciw seliong ko he tiensi.... Ansaw an hen seliong "(kalau mandi tak tentu ........ pagi-pagi turun ke kebun tak mandi... jam 9 pulang baru saya mandi... sore mandi lagi ... kecuali kemarau sering mandi, IND). 
"Ban sam...ban fu ju shi jin nyik ji lin...ju shipun liong nyik..... jilin he hi jantu sam ka fu enthung " (ganti baju...Celana kadang satu hari sekali....kadang-kadang juga dua hari sekali ..... kalau ke kebun baju, celana yang lain, $F G D$ ).

b. Konsep sehat sakit

Keadaan sehat bagi etnis Tionghoa (lanjut usia) dipandang sebagai suatu kondisi tidak adanya gangguan fisik. Sedangkan keadaan sakit dipahami sebagai suatu yang mengalami gangguan fisik, meskipun demam panas itu merupakan penyakit yang ringan. Seperti petikan berikut ini :

"Phot phang he'ju sim chong he chikkah hiaw hang... he fat shaw emboy
how... he bonsin lehen khong chuh moh sim chong “ (sakit kalau ada gangguan
fisik meskipun kita dapat berjalan... kalau demam itu sakit yang ringan... kalau
badan sehat berarti tidak ada gangguan fisik, FGD).

Proses kehidupan di dalam masyarakat selalu mengalami perubahan sesuai dengan cepat atau lambatnya perubahan tersebut. Begitu juga pada masyarakat etnis Tionghoa di pegunungan saliung, meskipun perubahan tersebut tidak diketahui munculnya dan sangat lambat. Perubahan yang terjadi adalah pengetahuan tentang konsep sehat sakit, khususnya pada keluarga muda yang baru berumah tangga, penyakit disebabkan masuknya penyakit ke dalam tubuh. Tetapi dalam pencarian pertolongan pengobatan, mereka tidak berubah. Perubahan pengetahuan konsep sehat sakit ini diakibatkan oleh peningkatan pendidikan, interaksi sosial yang dilakukan dan urbanisasi. Sebagaimana Susanto (1989), menyatakan bahwa perubahan itu disebabkan oleh majunya ilmu pengetahuan dan teknologi, komunikasi, transportasi, urbanisasi serta harapan dan tuntutan manusia (the rising demands).

\section{c. Pengetahuan Lanjut Usia}

1). Pemilihan makanan (Gizi) lanjut usia

Pada umumnya lanjut usia mengetahui kegunaan makanan bagi kesehatan tubuh. Sedangkan pemilihan makanan bergizi dan aturan makan merupakan suatu hal yang penting. Tetapi pengetahuan lanjut usia etnis Tionghoa di pegunungan Saliung tentang kegunaan makanan tersebut berbeda-beda. Hal ini sesuai dengan pengalaman dan kondisi tubuh dalam proses penerimaan makanan. Sebagaimana petikan berikut ini:

"Nghai ju shit tungsi kew ngai pungsi... ka'he ju' thusy hiuw na shuh he shit tungsi bongsin chitho....antung chikkah emoh shit ke tungsi"(saya 
biasanya makan sesuai dengan kemampuan uang dan kebiasaan perut menerimanya...kalau makan badan terasa sakit kita jangan memakan makanan itu, IND).

" Pongchi shit tungsi ka'choy coy bonsin anfund ka' ju'pu "(usahakan makan makanan yang sayuran...supaya badan segar dan ada vitaminnya, FGD).

2). Pengetahuan tentang petugas

Komunitas etnis Tionghoa (lanjut usia) dipegunungan Saliung menganggap bahwa yang lebih berperan dalam menginformasikan tentang perawatan kebersihan dan kesehatan itu, khususnya petugas yang dalam hal ini adalah perawat (mantri), bidan dan kader-kader yang ditunjuk oleh Puskesmas, sehingga Puskesmas dapat lebih berfungsi sebagai ujung tombak dalam bimbingan dan pembinaan masyarakat dalam bidang kesehatan khususnya perawatan kebersihan dan kesehatan lanjut usia.

\section{d. Sikap Lanjut usia}

Pemahaman tentang sikap masyarakat etnis Tionghoa (lanjut usia) dapat dipergunakan untuk memprediksi kemungkinan perilaku kesehatan masyarakat yang akan berdampak terhadap peningkatan status kesehatan. Sikap masyarakat juga dapat dijadikan bahan penilaian bagi keikutsertaannya dalam memanfaatkan pelayanan kesehatan.

1). Konsep sehat sakit

Sesuai dengan tingkat persepsi masyarakat etnis Tionghoa (lanjut usia) tentang konsep sehat sakit. Sikap yang muncul dari lanjut usia untuk menanggulangi peran sakit adalah sebisa mungkin dilakukan pengobatan sendiri dengan menggunakan obat tradisional Tionghoa atau obat warung sebagai pilihan pertama sebelum dilakukan pengobatan pada lau'ya, mantri atau dokter. Sebagaimana petikan berikuti ini:

" Heh nghai pot phiang....Ju si' sik jok shen kaksik jap sui hiauw thung nyet....He ju jik nyik phiang mang ho oy khiak-khiak hie jok chay tian may jok" "kalau saya sakit... biasanya obat dulu sendiri dengan minum daundaun penurun panas dan tergantung sakitnya.... kalau satu hari belum sembuh langsung beli obat warung, IND).

2). Upaya menjaga kesehatan lanjut usia

Ada cara-cara yang dilakukan lanjut usia untuk menjaga kesehatan dan mencegah timbulnya penyakit, seperti meminum- 
minuman ramuan tradisional Cina yang mereka namakan phu-jok, yaitu sejenis minuman untuk menjaga stamina agar tetap segar dan bergairah, minum arak obat dan ginseng yang diramu khusus untuk mencegah kuman-kuman masuk ke dalam tubuh seperti influenza, demam, batuk pilek. Selain itu menurut anggapan mereka bahwa kalau sering mengkonsumsi ramuan/rebusan dan minuman phu-jok, maka darah di dalam tubuh terasa pahit sehingga bibit penyakit tidak masuk ke dalam darah dan akan mati karena darah terasa pahit.

1) Dukungan Perawatan kebersihan dan kesehatan

a. Dukungan keluarga

Besarnya peranan keluarga dalam merawat lanjut usia sakit (anak-anak, saudara istri maupun suami) sangat besar). Anak laki-laki berfungsi sebagai pengganti orang tua untuk memenuhi kebutuhan hidupnya sehari-hari dan merawat lanjut usia. Selain itu bagi anak-anak lanjut usia yang berada di perantauan juga selalu mengirimkan obat dan dana keuangan untuk orang tua (lanjut usia) dan keluarganya.

b. Dukungan Masyarakat (tetangga)

Perhatian masyarakat/tetangga sangat besar, jika ada keluarga atau tetangga yang mengalami sakit. Mereka dapat bercerita tentang penderitaan yang dialami oleh si sakit, seakan-akan merekalah yang merasakan sakitnya, selain itu banyak juga tetangga yang berkunjung sambil memberikan sumbangan seadanya seperti beras, gula kopi, teh.

c. Dukungan pelayanan kesehatan

Peranan pelayanan kesehatan untuk lanjut usia etnis Tionghoa di pegungan Saliung secara khusus tidak ada. Dukungan pelayanan kesehatan yang diterima lanjut usia sama dengan kelompok umur yang lain. Satu-satunya sarana kesehatan yang dapat dijangkau oleh lanjut usia dipegunungan Saliung adalah Puskesmas tanjung batu.

d. Pengobatan Tradisional

Pengobatan tersebut seperti; dukun lau'ya, pengobatan Shinshe (tulang dan syaraf). 
4). Sumber daya

Wilayah pemukiman etnis Tionghoa dipegunungan saliung terletak diantara lahan persawahan dan sebagian hutan pegunungan saliung. Ladang lebih banyak berada di wilayah perbukitan, sedangkan kebun sayur berada di sekeliling pemukiman penduduk.

5). Sumber bahan Makanan

Sebagian besar bahan makanan untuk kebutuhan seharihari berasal dari kebun/ladang, seperti bayam, sawi, labu kuning, timun, terong, lobak, cabe besar dan cabe rawit, kacang panjang, kangkung dan gambas. Sumber bahan makanan dari hutan dalam seperti rebung, pakis, kulat (jamur kuping warna coklat), pucuk buas singkil, cempedak, durian dan lain sebagainya.

4. Pola Tinggal, Perawatan Kebersihan dan Kesehatan Lanjut Usia

Pola tinggal (nilai perilaku/keinginan) yang berasal dari lingkungan fisik, biologis dan psikologis akan mempengaruhi kesehatan lanjut usia. Lingkungan dalam arti yang luas (makro dan mikro). Selain mempengaruhi sumber-sumber pokok potensi daerah tinggal juga berpengaruh terhadap perilaku, tata nilai (sistem sosial) dan keyakinan. Termasuk di dalamnya adalah perawatan kebersihan dan kesehatan.

Masyarakat pada umumnya yang tinggal di daerah pegunungan dan komunitas etnis Tionghoa pada khususnya hidup sangat tergantung dari alam. Latar belakang hidup komunitas Tionghoa di pegunungan Saliung yang agraris tradisional menjadikan mereka terikat dengan alam sekitarnya. Kehidupan lanjut usia, semakin tua mereka kurang memperhatikan perawatan kebersihan diri. Aktivitas di kebun merupakan kegiatan rutin yang dilakukan setiap hari dari pagi hingga tengah hari, bahkan biasanya mereka sampai sore. Dengan aktivitas kerja yang banyak memakan waktu, pada akhirnya mereka meninggalkan kewajiban untuk memelihara kebersihan dan kesehatan pribadi seperti mandi, mengganti pakaian, membersihkan tangan, kaki kuku dan lain-lain.

\section{KESIMPULAN}

1. Pola tinggal lanjut usia di pegunungan Saliung lebih memilih tinggal di daerah yang luas (pegunungan) bersama anak, menantu dan cucu. Anak laki-laki dipilih karena sebagai pengganti lanjut usia sekaligus bertanggung jawab untuk memelihara orang tua sampai akhir hayatnya. Komunitas Tionghoa yang tetap mempertahankan dan memegang teguh tradisi, budaya dan kepercayaan leluhurnya sehingga semua ajaran- 
ajaran nenek moyang dilaksanakan dengan penuh keseriusan dan kepatuhan demi memperoleh kehidupan yang bahagia dan sejahtera. Lingkungan tempat tinggal (sarana, fasilitas rumah tempat tinggal) lebih dipandang sesuai dengan tradisi dan kepercayaan yakni "Fung-Shui" dan diyakini harus tinggal dalam satu komunitas etnis yang sama, agar lebih aman dan tenang.

2. Perawatan kebersihan diri lanjut usia berkaitan dengan aktivitas, waktu dan nilai-nilai tradisi (pantangan) sehingga perhatian terhadap perawatan kebersihan diri dan kesehatan sangat rendah. Pada umumnya keadaan kesehatan lansia cukup baik sehingga dapat melakukan aktivitas bekerja di kebun. Keluhan lansia umumnya terasa sakit di persendian atau sakit pada badan dan gatal-gatal (merah di badan).

3. Lanjut usia mengetahui bahwa pola tinggal yang baik, perawatan kebersihan diri sangat berhubungan dengan kesehatan, namun karena keterbatasan waktu dan aktivitas bekerja di kebun sehingga pelaksanaan hanya apabila badan terasa risih (kotor) dan gatal serta tubuh terasa tidak segar. Roh jahat yang bergentayangan dipercaya dapat mengganggu lanjut usia dan penyebab timbulnya suatu penyakit pada manusia (famtho).

4. Dukungan perawatan kebersihan diri dan kesehatan lanjut usia etnis Tionghoa di Pegunungan Saliung tidak terlepas dari keluarga, masyarakat (tetangga), pelayanan kesehatan dan pengobatan tradisional. Kepercayaan pada penyebab penyakit yang berasal dari roh-roh jahat (ghaib) menjadikan lau'ya fham-tho pada posisi yang dihormati dalam proses pengobatan.

5. Pengetahuan dan sikap masyarakat (lanjut usia) lebih banyak dipengaruhi oleh pengalaman-pengalaman sebagai bentuk pengamatan secara langsung terhadap diri dan lingkungan, serta pengalaman dan kebiasaan nenek moyang/leluhurnya dahulu. Sedangkan pengetahuan petugas tentang masyarakat etnis Tionghoa di Saliung terbatas mengetahui wilayah setempat dan penghuninya yang khas (Cina Tionghoa).

\section{SARAN}

1. Pemerintah Daerah setempat, agar lebih memberikan perhatian dan kepedulian (moril dan matril) kepada penduduk lansia, khususnya komunitas etnis Tionghoa yang berada di wilayah pegunungan Saliung 
2. Dalam pelaksanaan informasi program kesehatan masyarakat (penduduk lansia) pada komunitas etnis Tionghoa, agar dapat melibatkan keluarga (anak-anak lansia) dan para tokoh masyarakat etnis Tionghoa.

3. Dukungan perawatan kebersihan dan kesehatan dapat lebih ditingkatkan melalui informasi, komunikasi dan menggerakkan kembali program kegiatan pos pelayanan terpadu bagi penduduk lanjut usia yang selama ini mengalami kepakeman. Dengan demikian penduduk lanjut usia dapat hidup lebih aktif, produktif untuk mengurus dirinya (perawatan, kebersihan dan kesehatan), sehingga lanjut usia selalu bersih, sehat dan bahagia hingga akhir hayatnya.

\section{DAFTAR PUSTAKA}

Brubaker T.H. (1994), Aging, Health and Family New Delhi: Sage Publications.

Emilia, O, Hasanbasri, M., Prabandari Y.S., Dasuki D. (1995), Penduduk Usia Lanjut di Prop. DIY : Studi Kualitatif terhadap permasalahan usila, Berita kedokteran Masyarakat, XI (2), (43-46).

Faturrochman dan Kusumasari, (2001), Kondisi Sosial Ekonomi Penduduk Lanjut Usia di kota Yogyakarta : PPSK UGM.

Hayati, (1997), Lansia masa depan yang tak dapat dihindar. Majalah Kesehatan, 151, 51-55.

Matindas, D., (1994), Aspek Psikologi pada Lanjut Usia, Majalah Kedokteran Indonesia, Volume 44 Nomor 9 (the journal of the Indonesian Medical Association), Jakarta, H. 41-43.

Messent PR, (1998), Daily Physical Aktivity in Adult With and Moderate Learning Rehabilitation, 20 (11). H. 7-12.

Miles, M.B. dan Huberman. A.M., (1992), Analisis Data Kualitatif. Alih Bahasa oleh Tjetjep Rohendi Rohidi, Jakarta : UI-Press.

Moleong, Lexy J., (2002), Metodologi Penelitian Kualitatif. Bandung : Penerbit Remaja Karya Offset.

Murti, B., (1997), Kualitas hidup, Isu Konseptual dan Pengukuran Medika. No.6 Tahun XXIII Jakarta, h. 473-475.

Muhadjir, L. (1996), Metodologi Penelitian Kualitatif. Bandung: PT. Remaja Rosda Karya. 
Nurrochmah, (1998), Perilaku keluarga terhadap Kesehatan dan keadaan sakit: Sebuah model pendekatan. Jurnal Keperawatan Indonesia Vol 1 N0.4 FKUI Jakarta (91-96).

Policy Brief, 2001, Alternatif Kebijakan Terhadap Lansia CPSS No. 07/PB/2001, Gadjah Mada University.

Silaswati, S., (2000), Pendekatan Multi Disipliner sebagai Alternatif Manajemen kasus Lanjut usia, Majalah Keperawatan Bina sehat PPNI. Edisi Mei/Juni Vol. No. 003/BS/PPNI. h. 39-41.

Rahayu, R.A., (1996), Aspek Sosio Ekonomi Pada Lansia, Makalah Pelatihan Geriatri Tingkat Nasional 